\title{
Crescimento e produção de antúrio submetido a diferentes intensidades de desfolha
}

\author{
Growth and production of anthurium submitted to different defoliation intensities
}

\author{
Edson Shigueaki Nomura $^{{ }^{*}}$ Juliana Domingues Lima ${ }^{I I}$ Eduardo Jun FuzitaniI \\ Silvia Helena Modenese-Gorla da Silva ${ }^{\text {II }}$ Valéria Augusta Garcia ${ }^{I}$ \\ Antonio Fernando Caetano Tombolato ${ }^{\text {III }}$
}

\section{RESUMO}

\begin{abstract}
$O$ objetivo do presente trabalho foi avaliar o crescimento e a produção de Anthurium andraeanum 'Apalai' submetido a diferentes intensidades de desfolha no Vale do Ribeira, SP. Foram utilizadas mudas micropropagadas dessa espécie, as quais foram plantadas em canteiros construídos sob telado coberto com tela de náilon preta, com malha que proporciona $70 \%$ de sombreamento, no espaçamento 0,40x0,40m. O experimento foi conduzido em delineamento de blocos casualizados em parcelas subdivididas, com dezesseis repetições. $O$ efeito da desfolha foi avaliado na parcela e o efeito do tempo após a desfolha na subparcela. As diferentes intensidades de desfolha consistiram em plantas com três, quatro e cinco folhas e plantas sem desfolha, e o tempo após a desfolha, as avaliações realizadas em 2006 e 2007. Ocorreu um aumento na área das folhas individuais em plantas mantidas com quatro e cinco folhas, proporcional à intensidade de desfolha, que pode ser relacionado a uma tentativa de compensação da área foliar perdida. A desfolha com a manutenção de três, quatro ou cinco folhas em plantas de antúrio 'Apalai' é prejudicial para o seu crescimento e produção.
\end{abstract}

Palavras-chave: Anthurium andraeanum, poda de folha, área foliar, prática de manejo.

\section{ABSTRACT}

The aim of this research was to evaluate the growth and yield of Anthurium andraeanum 'Apalai' submitted to different defoliation intensities in Vale do Ribeira, SP. In order to develop this research, micropropagated seedlings of this species were used, planted in beds built under a roof covered with a black nylon screen, with a mesh that provides $70 \%$ shading, spaced $0.40 \times 0.40 \mathrm{~m}$ apart. The experiment was

\begin{abstract}
conducted in a randomized block design in split splot with sixteen replicates. The defoliation effect was evaluated in the whole plots and the effect of time after defoliation was evaluated in the split-plots. The different defoliation intensities consisted of plants with three, four and five leaves and plants without defoliation, and the time after defoliation. Assessments were conducted in 2006 and 2007. There was an increase in the area of individual leaves in plants maintained with four and five leaves, proportional to the defoliation intensity, which may be related to an attempt to offset the lost leaf area. Defoliation caused by the maintenance of three, four or five leaves in anthurium 'Apalai' plants is detrimental to their growth and production.
\end{abstract}

Key words: Anthurium andraeanum, leaf pruning, leaf area, management practice.

\section{INTRODUÇÃO}

Dentre as espécies tropicais importantes para floricultura brasileira e para região do Vale do Ribeira, SP, destaca-se o antúrio (Anthurium andraeanum Lind.), que é uma monocotiledônea originária da Colômbia, pertencente à família Araceae (COLLETTE et al., 2004), cuja haste floral comercializável é uma inflorescência composta de bráctea colorida (espata) e de uma pequena espiga (espádice), com flores verdadeiras (HIGAKI et al., 1984).

O antúrio é uma planta perene de crescimento lento que exige condições de calor, umidade

'Agência Paulista de Tecnologia dos Agronegócios (APTA), Pólo Regional Vale do Ribeira, Rod. Régis Bittencourt, BR-116, Km 460, CP 122, 11900-000, Registro, SP, Brasil. E-mail: edsonnomura@apta.sp.gov.br. *Autor para correspondência.

"Campus Experimental de Registro, Universidade Estadual Paulista "Júlio de Mesquita Filho" (UNESP), Registro, SP, Brasil.

IIIAgência Paulista de Tecnologia dos Agronegócios (APTA), Instituto Agronômico (IAC), Campinas, SP, Brasil. 
e sombra, ocorrendo em florestas tropicais úmidas (DONSELMAN \& BROSCHAT, 1988; COLLETTE et al., 2004; DUFOUR \& GUÉRIN, 2005). Seu desenvolvimento compreende duas fases distintas, a primeira corresponde à fase juvenil monopodial, e a segunda, à fase reprodutiva simpodial, durante a qual uma inflorescência é produzida em cada axila da folha (HIGAKI et al., 1984), mantendo a sequência folha e inflorescência, folha e inflorescência durante todo o ciclo de vida da planta, dependendo das condições ambientais e nutricionais.

Em estudo realizado para determinação da função da folha no crescimento da haste floral de antúrio, DAÏ \& PAULL (1990) observaram que a remoção de folhas maduras com alta taxa de fotossíntese não causou efeito adverso na produção e qualidade das hastes florais. A remoção da folha ainda jovem, não completamente expandida, com taxa fotossintética negativa, acelerou a emissão da haste floral e também não afetou a produção e a qualidade. Concluíram que a emissão das folhas compete com a emissão da haste floral por fotoassimilados. Assim, o crescimento da haste floral depende da relação fontedreno da planta e pode ser favorecido pela redução dos drenos ou aumento da fonte (DUFOUR \& GUÉRIN, 2003).

Em países produtores de antúrio para flor de corte como a Malásia (THE MINISTRY OF AGRICULTUREANDAGROBASED INDUSTRY, 2004), o Havaí (HIGAKI et al., 1994) e a Índia (NIIR BOARD, 2004) recomendam a desfolha e a manutenção de apenas quatro folhas na planta. Considerando-se que as práticas culturais devem ser estabelecidas em função do genótipo e das condições edafoclimáticas, o objetivo do presente trabalho foi avaliar o crescimento e a produção de antúrio 'Apalai' submetido a diferentes intensidades de desfolha na região do Vale do Ribeira.

\section{MATERIAL E MÉTODOS}

O experimento foi conduzido no sítio Oriente, localizado no município de Pariquera-Açu, SP, de 2006 a 2007. Utilizou-se o delineamento experimental inteiramente casualizado, em parcelas subdivididas, com dezesseis repetições. O efeito da desfolha foi avaliado na parcela, e o efeito do tempo após a desfolha, nas subparcelas. As diferentes intensidades de desfolha consistiram em plantas com três, quatro e cinco folhas e plantas sem desfolha, e o tempo após a desfolha, as avaliações realizadas em 2006 e 2007.

O material vegetal consistiu em plantas de Anthurium andraeanum 'Apalai' obtidas por meio de micropropagação e aclimatadas, medindo cerca de $20 \mathrm{~cm}$ de altura. O plantio foi realizado em agosto de 2004, em canteiros com 1,2m de largura, construídos sob telado com 3,0m de pé-direito e coberto com tela de náilon cuja malha preta proporcionou $70 \%$ de sombreamento, sendo o espaçamento entre plantas de $0,40 \times 0,40 \mathrm{~m}$. Na adubação de produção, foram aplicados $50 \mathrm{~g} \mathrm{~m}^{-2}$ do adubo NPK de fórmula 10-10-10 a cada dois meses, de agosto até abril de cada ano. Foram também distribuídos $0,02 \mathrm{~m}^{3} \mathrm{~m}^{-2}$ de serragem na superfície dos canteiros para manter a umidade do solo e diminuir a incidência de plantas daninhas. Periodicamente, após a colheita das hastes florais, quando necessário, a folha mais velha da planta foi removida, conforme os tratamentos estabelecidos.

As avaliações foram iniciadas após a produção de hastes florais comercializáveis, sendo realizadas durante 24 meses. Para tal, semanalmente, as inflorescências foram colhidas quando a espádice apresentava metade a três quartos das flores verdadeiras abertas, estimada pela mudança de coloração da base para o ápice da espádice e, em seguida, tomadas as suas medidas: comprimento da haste floral, comprimento da espata, largura da espata e comprimento da espádice. Adicionalmente, a cada 60 dias, foram determinadas as dimensões foliares, como o comprimento do pecíolo, a largura e o comprimento da folha. A área foliar total da planta foi calculada por meio da somatória da área das folhas individuais, estimada pela equação $\mathrm{AF}=0,9672 * \mathrm{C} * \mathrm{~L}$ (MODENESEGORLA DA SILVA et al., 2008), em que AF é a área foliar, C e L são, respectivamente, o comprimento e a largura da folha.

Os dados obtidos foram submetidos à análise de variância, sendo que as médias foram comparadas através do teste de Tukey, a 5\% de probabilidade. Foi realizada também a análise de regressão polinomial para as variáveis índice de área foliar total, média por folha e individual, para identificar a evolução dessas variáveis com o passar do tempo, sendo a escolha da regressão baseada na significância do coeficiente de determinação das equações obtidas e teste $\mathrm{t}$ a $5 \%$ de probabilidade.

\section{RESULTADOS E DISCUSSÃO}

Todas as características morfológicas das hastes florais foram afetadas pela desfolha e época de cultivo (Tabela 1). As dimensões médias dessas características, independente da intensidade de desfolha, foram mais elevadas em 2007, em relação a 2006, indicando maior crescimento com a idade da planta, também observado por DUFOR \& GUÉRIN (2003). 
Tabela 1 - Características morfológicas médias de hastes florais de antúrio 'Apalai' submetido à desfolha: comprimento da haste floral (CHF); comprimento da espata (CESP); largura da espata (LESP); comprimento da espádice (CESPD). Pariquera-açu, SP, 2006 e 2007.

\begin{tabular}{|c|c|c|c|c|c|c|c|c|c|c|c|c|c|c|c|}
\hline \multirow{3}{*}{$\begin{array}{l}\text { Tratamentos } \\
\text { Sem desfolha }\end{array}$} & \multicolumn{4}{|c|}{--------CHF (cm)------- } & \multicolumn{4}{|c|}{--------CESP (cm)-------- } & \multicolumn{4}{|c|}{--------LESP (cm)--------- } & \multicolumn{3}{|c|}{-------CESPD (cm)------ } \\
\hline & \multicolumn{2}{|c|}{2006} & \multicolumn{2}{|c|}{2007} & \multicolumn{2}{|c|}{2006} & \multicolumn{2}{|c|}{2007} & \multicolumn{2}{|c|}{2006} & \multicolumn{2}{|c|}{2007} & \multicolumn{2}{|c|}{2006} & 2007 \\
\hline & 42,62 & $\mathrm{Ab}$ & 49,18 & $\mathrm{Aa}$ & 10,29 & $\mathrm{Ab}$ & 11,23 & $\mathrm{Aa}$ & 12,73 & $\mathrm{Aa}$ & 13,56 & $\mathrm{Aa}$ & 7,69 & $\mathrm{Ab}$ & $8,26 \quad \mathrm{Aa}$ \\
\hline 5 folhas & 42,10 & $\mathrm{Ab}$ & 49,91 & $\mathrm{Aa}$ & 10,09 & $\mathrm{ABb}$ & 11,23 & $\mathrm{Aa}$ & 12,70 & $\mathrm{Aa}$ & 13,53 & $\mathrm{Aa}$ & 7,76 & $\mathrm{Ab}$ & 8,29 Aa \\
\hline 4 folhas & 39,51 & $\mathrm{Bb}$ & 49,47 & $\mathrm{Aa}$ & 9,61 & $\mathrm{BCb}$ & 10,71 & $\mathrm{Aa}$ & 12,08 & $\mathrm{Bb}$ & 13,14 & $\mathrm{Aa}$ & 7,31 & $\mathrm{Bb}$ & $7,80 \quad \mathrm{Ba}$ \\
\hline 3 folhas & 37,50 & $\mathrm{Bb}$ & 42,86 & $\mathrm{Ba}$ & 9,11 & $\mathrm{Cb}$ & 9,90 & $\mathrm{Ba}$ & 11,55 & $\mathrm{Ba}$ & 12,28 & $\mathrm{Ba}$ & 7,08 & $\mathrm{Ba}$ & $7,36 \quad \mathrm{Ca}$ \\
\hline Média & 40,43 & $\mathrm{~b}$ & 47,86 & $\mathrm{a}$ & 9,78 & $\mathrm{~b}$ & 10,76 & $\mathrm{a}$ & 12,26 & $\mathrm{~b}$ & 13,13 & $\mathrm{a}$ & 7,46 & $\mathrm{a}$ & $7,92 \quad b$ \\
\hline $\mathrm{CV}_{1} \%$ & \multicolumn{4}{|c|}{15,93} & \multicolumn{4}{|c|}{13,05} & \multicolumn{4}{|c|}{12,95} & \multicolumn{3}{|c|}{11,19} \\
\hline $\mathrm{CV}_{2} \%$ & \multicolumn{4}{|c|}{5,84} & \multicolumn{4}{|c|}{5,48} & \multicolumn{4}{|c|}{4,79} & \multicolumn{3}{|c|}{3,71} \\
\hline
\end{tabular}

Médias não seguidas da mesma letra maiúscula na coluna e minúscula na linha diferem entre si, a 5\% de probabilidade, pelo teste de Tukey. $\mathrm{CV}_{1}$ : coeficiente de variação da parcela; $\mathrm{CV}_{2}$ : coeficiente de variação da subparcela.

O comprimento médio da haste floral (CHF), em 2006, foi 40,43cm e, em 2007, de 47,86cm (Tabela 1), valores baixos e inadequados, considerando que o comprimento mínimo recomendado como requisito para comercialização é de $60 \mathrm{~cm}$ (TOMBOLATO et al., 2002). Em 2006, plantas sem desfolha e mantidas com cinco folhas produziram hastes florais com comprimento médio superior às plantas cultivadas com três e quatro folhas. Todavia, em 2007, plantas sem desfolha, com cinco e quatro folhas não diferiram quanto ao comprimento da haste floral, que foram superiores às colhidas em plantas mantidas com três folhas.

O comprimento médio da espata (CESP) foi cerca de 9,78 e $10,76 \mathrm{~cm}$, respectivamente, no ano de 2006 e 2007 (Tabela 1). Em 2006, plantas sem desfolha e com cinco folhas não diferiram entre si quanto ao comprimento da espata, o mesmo ocorre com plantas com quatro e cinco folhas. No entanto, plantas sem desfolha e com cinco folhas apresentaram comprimento da espata superior a plantas mantidas com três folhas. Em 2007, o menor comprimento da espata ocorreu em plantas mantidas com três folhas, que diferiram dos demais tratamentos.

Hastes florais colhidas em 2006 tiveram em média de $12,26 \mathrm{~cm}$ de largura (LESP), enquanto as colhidas em 2007, largura média igual a 13,13cm (Tabela 1). Em 2006, plantas sem desfolha e com cinco folhas tiveram largura da espata superior a plantas com três e quatro folhas. Em 2007, a menor largura da espata foi observada em plantas com três folhas.

Em 2006, os menores comprimentos da espádice (CESPD) foram observados em plantas com três e quatro folhas e, em 2007, em plantas com três folhas. Contudo, esta variável não tem sido utilizada como padrão de classificação de qualidade (Tabela 1).
Plantas de antúrio 'Apalai', cultivadas em vaso por 36 meses no norte do Paraná, apresentaram valores médios do comprimento da haste floral, comprimento e largura da espata e comprimento da espádice, respectivamente, de 51,6; 9,4; 8,1 e 5,3cm, além de a taxa de crescimento absoluto das folhas ser baixa e até mesmo negativa nos meses mais frios do ano(TAKAHASHI et al., 2009). Comparando as hastes florais colhidas em 2006, ano em que as plantas atingiram 36 meses, com as dimensões das obtidas por TAKAHASHI et al. (2009) na mesma cultivar, observam-se valores inferiores para o comprimento da haste floral, porém superiores para comprimento e largura da espata e comprimento da espádice (Tabela 1). Todavia, TAKAHASHI et al. (2009) utilizaram $80 \%$ de sombreamento, enquanto, neste estudo, $70 \%$ de sombreamento. Em geral, quanto maior o nível de sombreamento maior é o comprimento do caule e pecíolo, que é uma resposta morfogênica típica das plantas à restrição da luz (FRANKLIN \& WHITELAM, 2005), o que pode explicar o maior comprimento da haste floral nas plantas cultivadas por TAKAHASHI et al. (2009).

Nas plantas com crescimento livre, ou seja, sem desfolha, o número de folhas por planta variou de 7,2 a 9,6, respectivamente, 60 a 600 dias após o início dos tratamentos. Isso significa que as plantas mantidas com cinco folhas apresentaram duas a quatro folhas a menos que as mantidas sem desfolha, enquanto plantas mantidas com quatro folhas, três a quatro folhas a menos e plantas mantidas com três folhas, quatro a seis folhas a menos.

Como esperado, plantas que sofreram desfolha apresentaram redução da área foliar total proporcional ao número de folhas removidas (Figura 1A). 


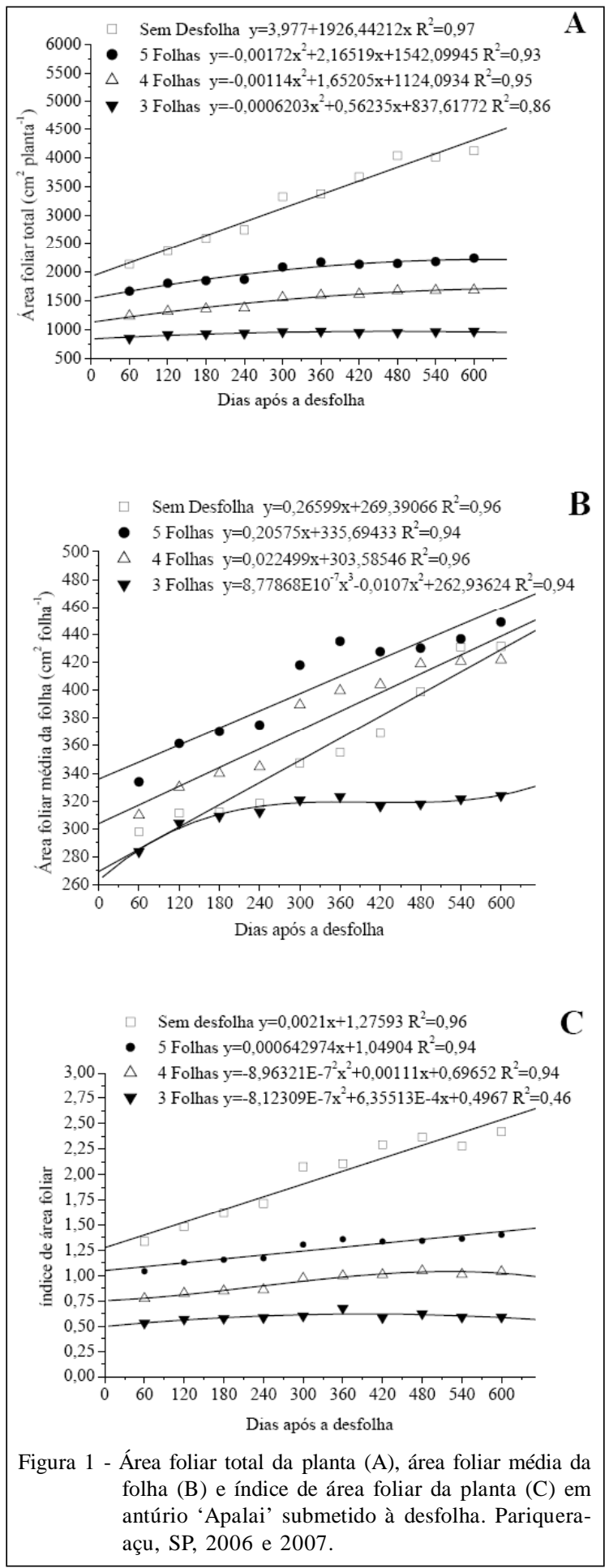

Em plantas mantidas sem desfolha, o incremento da área foliar foi linear durante os dois anos de avaliação, enquanto que em plantas submetidas à desfolha, independentemente do número de folhas removidas, $\mathrm{o}$ incremento teve comportamento quadrático (Figura 1A).
O incremento na área foliar em plantas sem desfolha parece ter sido pouco influenciado pelo clima, que apresentou variações significativas na temperatura e precipitação (dados não apresentados), excedendo em alguns meses a temperatura mínima basal de $14^{\circ} \mathrm{C}$ (DUFOUR \& GUÉRIN, 2003), contudo, sem exceder a temperatura máxima basal de $35^{\circ} \mathrm{C}$ (TOMBOLATO et al., 2002).

Em plantas mantidas sem desfolha, com cinco e quatro folhas, houve aumento na área foliar média das folhas ao longo do tempo, também observado na mesma espécie por DUFOR \& GUÉRIN (2003). Esse aumento foi, inicialmente, mais elevado nas plantas mantidas com cinco folhas, seguida das plantas mantidas com quatro folhas, quando comparadas com plantas não desfolhadas (Figura 1B). No caso de plantas com desfolha menos acentuada, o maior tamanho pode refletir uma tentativa de compensar a área foliar removida, resposta não observada em plantas mantidas com três folhas. Essa alteração é comumente observada e é devido principalmente ao aumento na expansão celular, ou, ainda, ao aumento na divisão celular (CASTRO \& GARCIA, 1996). Provavelmente em plantas mantidas com três folhas, a redução da área foliar comprometeu a expansão das folhas, bem como a emissão de hastes florais, o que explica o menor desempenho em termos de crescimento e produção.

O índice de área foliar (IAF) representa a área foliar total por unidade de área do terreno e indica a superfície disponível para interceptação da luz. Esse índice apresentou comportamento linear em plantas sem desfolha e com cinco folhas e quadrático em plantas com quatro folhas (Figura 1C). No entanto, utilizando os modelos linear e quadrático, não foi possível um ajuste significativo para o IAF em plantas mantidas com três folhas. O IAF médio em plantas sem desfolha, com cinco, quatro e três folhas foi, respectivamente, 1,$97 ; 1,26 ; 0,94$ e 0,54 .

Com relação à produção, o número de hastes florais (NHF) foi influenciado pela desfolha nos dois anos de cultivo (Tabela 2), sendo mais elevado em plantas sem desfolha quando comparadas com os demais tratamentos, que não diferiram entre si. Independente da intensidade de desfolha, o número médio de hastes florais produzidas em 2006 foi mais alto quando comparado com 2007. O menor intervalo de florescimento (IFLOR), em 2006 e 2007, foi observado em plantas sem desfolha, seguida de plantas com cinco e quatro folhas, que não diferiram entre si e, posteriormente, de plantas com três folhas. A maior diferença para intervalo de florescimento ocorreu entre plantas sem desfolha e plantas com três folhas, e foi 
Tabela 2 - Número de hastes florais (NHF) e intervalo de florescimento (IFLOR) em antúrio 'Apalai' submetido à desfolha. Pariquera-açu, SP, 2006 e 2007.

\begin{tabular}{|c|c|c|c|c|}
\hline \multirow{3}{*}{$\begin{array}{l}\text { Tratamentos } \\
\text { Sem desfolha }\end{array}$} & \multicolumn{2}{|c|}{----------------------NHF----------------------- } & \multicolumn{2}{|c|}{ - } \\
\hline & 2006 & 2007 & 2006 & 2007 \\
\hline & 6,13 Aa & $5,56 \mathrm{Ab}$ & $65,0 \quad \mathrm{Ca}$ & $65,7 \mathrm{Ca}$ \\
\hline 5 folhas & $5,56 \mathrm{Ba}$ & 5,38 Аа & $69,4 \quad \mathrm{Ba}$ & $70,9 \mathrm{Ba}$ \\
\hline 4 folhas & $5,50 \quad \mathrm{Ba}$ & $5,38 \mathrm{Aa}$ & $69,9 \quad \mathrm{Ba}$ & $69,2 \mathrm{Ba}$ \\
\hline 3 folhas & $5,31 \quad \mathrm{Ba}$ & $4,75 \mathrm{Bb}$ & 74,1 Аа & 74,7 Aa \\
\hline Média & 5,63 a & $5,27 \mathrm{~b}$ & 69,6 a & 70,2 a \\
\hline $\mathrm{CV}_{1} \%$ & \multicolumn{2}{|c|}{9,41} & \multicolumn{2}{|c|}{12,18} \\
\hline $\mathrm{CV}_{2} \%$ & \multicolumn{2}{|c|}{5,59} & \multicolumn{2}{|c|}{10,87} \\
\hline
\end{tabular}

Médias não seguidas da mesma letra maiúscula na coluna e minúscula na linha diferem entre si, a 5\% de probabilidade, pelo teste de Tukey. $\mathrm{CV}_{1}$ : coeficiente de variação da parcela; $\mathrm{CV}_{2}$ : coeficiente de variação da subparcela.

cerca de 9 dias entre os anos de 2006 e 2007. O número médio de hastes florais produzidas em 2006 e 2007 em plantas sem desfolha foi, respectivamente, de 6,13 e 5,56 por ano, com intervalo de florescimento médio, respectivamente, de 65,03 e 65,74 dias (Tabela 2), valores próximos ao obtidos por NOMURA et al. (2009).

As folhas constituem o aparato fotossintético da planta e são responsáveis pela formação de carboidratos, que são alocados para os órgãos vegetativos e reprodutivos das plantas (BASTOS et al., 2002). Assim, qualquer fator que interfira na área foliar pode afetar a produção (PELUZIO et al., 2002). O efeito positivo da redução da área foliar pode ocorrer em decorrência da redução do sombreamento, que promove o aumento da fotossíntese líquida nas folhas remanescentes (KHAN \& LONE, 2005). O efeito negativo, que provavelmente ocorreu neste estudo, é devido à redução da capacidade fotossintética da planta e, consequentemente, menor disponibilidade de fotoassimilados para o crescimento e produção (Tabela 1; Tabela 2). Em plantas sem desfolha, o IAF em função do tempo apresentou comportamento linear (Figura 1C), indicando que o IAF ótimo, que permite máxima interceptação de luz, não foi atingido, podendo ainda ocorrer aumento da área foliar pelo aumento do número de folhas ou do tamanho da folha, o que concorda com o comportamento da área foliar total (Figura 1A) e o tamanho médio da folha terem apresentado comportamento linear (Figura 1B).

$\mathrm{O}$ fato de as diferentes intensidades de desfolha terem prejudicado o crescimento e produção do antúrio, também pode indicar que não havia área foliar sombreada atuando como dreno dos fotoassimilados e que o IAF ótimo não tinha sido atingido. No entanto, o espaçamento utilizado foi $0,40 \times 0,40 \mathrm{~m}$, enquanto em outros países são adotados espaçamentos menores, tais como: $0,35 \mathrm{x} 0,35 ; 0,30 \mathrm{x} 0,30$ ou 0,30x0,25m (HIGAKI et al., 1994; NIIR BOARD, 2004; THE MINISTRY OF AGRICULTURE AND AGROBASED INDUSTRY, 2004), além de sombreamento mais elevado (80\%). Tais condições implicam, respectivamente, densidades populacionais mais altas e menor disponibilidade de radiação fotossinteticamente ativa, que podem tornar a desfolha prática cultural benéfica e necessária e, em contrapartida, promover maior produção de hastes florais por área.

\section{CONCLUSÃO}

A desfolha com a manutenção de três, quatro ou cinco folhas em plantas de antúrio 'Apalai' é prejudicial para o seu crescimento e produção.

\section{REFERÊNCIAS}

BASTOS, E.A. et al. Parâmetros de crescimento do feijão caupi sob diferentes regimes hídricos. Engenharia Agrícola, v.22, n.1, p.43-50, 2002.

CASTRO, C.R.T. de; GARCIA, R. Competição entre plantas com ênfase no recurso luz. Ciência Rural, v.26, n.1, p.167174, 1996. Disponível em: <http://www.scielo.br/ scielo.php?script=sci_arttext\&pid=S01038478199600010003 $1 \& \operatorname{lng}=$ en\&nrm=iso\&tlng=pt $>$. Acesso em: 10 fev. 2010. doi: $10.1590 / \mathrm{S} 0103-84781996000100031$.

COLLETTE, V.E. et al. Temporal and spatial expression of flavonoid biosynthetic genes in flowers of Anthurium andraeanum. Physiologia Plantarum, v.122, n.3, p.297304, 2004. Disponível em: <http://www3.interscience.wiley.com/ cgi-bin/fulltext/118761191/PDFSTART>. Acesso em: 05 fev. 2010. doi: 10.1111/j.1399-3054.2004.00402.x.

DAII, J.; PAULL, R.E. The role of leaf development in Anthurium andraeanum inflorescence growth. Journal American Society Horticulture Science, v.115, n.6, p.901-905, 1990. 
DONSELMAN, H.; BROSCHAT, T.K. Promising anthurium species and hybrids for the nursery industry. Proceedings of the Florida State Horticultural Society, v.101, n.2, p.341343, 1988. Disponível em: <http://www.fshs.org/Proceedings/ Password\%20Protected/1988\%20 Vol.\%20101/341 $343 \% 20$ (DONSELMAN).pdf>. Acesso em: 05 fev. 2010.

DUFOUR, L.; GUÉRIN, V. Growth, developmental features and flower production of Anthurium andraeanum Lind. in tropical conditions. Scientia Horticulturae, v.98, n.1, p.2535, 2003. Disponível em: <http://192.192.148.121/hhf/data/ attach/1_adnKi3.pdf>. Acesso em: 05 fev. 2010. doi:10.1016/ S0304-4238(02)00196-6.

DUFOUR, L.; GUÉRIN, V. Nutrient solution effects on the development and yield of Anthurium andraeanum Lind., in tropical soilless conditions. Scientia Horticulturae, v.105, n.2, p.269-282, 2005. Disponível em: <http://nhjy.hzau.edu.cn/ kech/ssyy/qysd/wtzp/13.pdf>. Acesso em: 05 fev. 2010. doi:10.1016/j.scienta.2005.01.022.

FRANKLIN, K.A.; WHITELAM, G.C. Phytochromes and shadeavoidance responses in plants. Annals of Botany, v.96, n.2, p.169-175, 2005. Disponível em: <http://aob.oxfordjournals.org/ content/96/2/169.full.pdf+html>. Acesso em: 23 out. 2010. doi: $10.1093 / \mathrm{aob} / \mathrm{mci} 165$.

HIGAKI, T. et al. A study of some morphological and anatomical aspects of Anthurium andraeanum Lind. Honolulu: University of Hawaii, 1984. 12p. (HITHAR Research Series, 30).

HIGAKI, T et al. Anthurium culture in Hawaii. Honolulu: University of Hawaii, 1994. 22p. (HITHAR Research EXTENSION Series, 152).

KHAN, N.A.; LONE, P.M. Effects of early and late season defoliation on photosynthesis, growth and yield of mustard (Brassica juncea L.). Brazilian Journal Plant Physiology, v.17, n.1, p.181-186, 2005. Disponível em: <http://www.scielo.br/ scielo.php?script $=$ sci_arttext $\&$ pid $=$ S167704202005000100015\& lng=en\&nrm=iso>. Acesso em: 23 out. 2010 . doi: 10.1590/ S1677-04202005000100015.

MODENESE-GORLA DA SILVA, S.H. et al. estimativa da área foliar do antúrio com o uso de funções de regressão. Ciência Rural, v.38, n.1, p.243-246, 2008. Disponível em: <http:// www.scielo.br/pdf/cr/v38n1/a40v38n1.pdf $>$. Acesso em: 05 fev. 2010. doi: 10.1590/S0103-84782008000100040.

NOMURA, E.S. et al. Crescimento e produção de antúrio cultivado sob diferentes malhas de sombreamento. Ciência Rural, v.39, n.5, p.1394-1400, 2009. Disponível em: <http:/ /www.scielo.br/pdf/cr/v39n5/a14v39n5.pdf>. Acesso em: 05 fev. 2010 .

NIIR BOARD. Tropical, subtropical fruits and flowers cultivation. Delhi: National Institute of Industrial Research, 2004. 600p.

PELUZIO, J.M. et al. Influência do desfolhamento artificial no rendimento de grãos e componentes de produção da soja [Glycine $\max$ (L.) Merrill]. Ciência e Agrotecnologia, v.26, n.6, p.1197-1203, 2002. Disponível em: <http://www.editora.ufla.br/ revista/26_6/art11.PDF>. Acesso em: 05 fev. 2010.

TAKAHASHI, L.S.A. et al. Desenvolvimento de cultivares de 'antúrio IAC' como plantas de vaso no norte do Paraná. Bragantia, v.68, n.3, p.593-600, 2009. Disponível em: <http:/ /www.scielo.br/pdf/brag/v68n3/a05v68n3.pdf>. Acesso em: 05 fev. 2010. doi: 10.1590/S0006-87052009000300005.

THE MINISTRY OF AGRICULTURE AND AGRO-BASED INDUSTRY. Technical document for market access on anthurium. Kuala Lumpur: Crop Protection and Plant Quarentine Services Division, 2004. 44p. (Technical Document).

TOMBOLATO et al. O cultivo de Antúrio: produção comercial. Campinas: Instituto Agronômico, 2002. 47p. (Série Tecnologia APTA, Boletim Técnico IAC, 194). 